\title{
Conversion of Industrial Food Wastes Cranberry Pomace into Foods Blending with Rice Flour using Single-screw Extrusion Process
}

\author{
Pranabendu Mitra (Corresponding author) \\ Department of Kinesiology, Health, Food and Nutritional Sciences, University of \\ Wisconsin-Stout, Menomonie, WI, 54751, USA \\ Tel: 1-715-232-5332_E-mail: mitrap@uwstout.edu
}

\begin{abstract}
Sagar Khanvilkar
Department of Kinesiology, Health, Food and Nutritional Sciences, University of Wisconsin-Stout, Menomonie, WI, 54751, USA
\end{abstract}

Sai Kumar Samudrala

Department of Kinesiology, Health, Food and Nutritional Sciences, University of Wisconsin-Stout, Menomonie, WI, 54751, USA

Kaushal Sunil Shroff

Department of Kinesiology, Health, Food and Nutritional Sciences, University of Wisconsin-Stout, Menomonie, WI, 54751, USA

Received: December 18, 2021 Accepted: December 31, 2021 Published: January 4, 2022

doi:10.5296/jfi.v5i1.19427ＵRL: http://dx.doi.org/10.5296/jfi.v5i1.19427

\begin{abstract}
The main objective of this study was to convert the cranberry pomace into value-added extruded cereals/snacks blending with rice flour using a single screw extruder based on the physicochemical properties of extrudates because utilization of the byproduct cranberry pomace would be necessary for the growth of cranberry juice processing industries and the extruded snacks/cereals with higher fiber and antioxidant and less carbohydrate would be required to fulfill the consumers' demand. The six different formulations by blending $0,5,10$,
\end{abstract}




\section{Macrothink}

15,20 and $25 \%$ cranberry pomace with $100,95,90,85,80$ and $75 \%$ of rice flour, respectively, were extruded using a single screw extruder. The temperature $\left(150^{\circ} \mathrm{C}\right)$, screw speed $(270$ $\mathrm{rpm})$, feed rate $(20 \mathrm{Kg} / \mathrm{hr})$ and feed moisture content (35\%) were constant during extrusion. The physicochemical properties of the extrudates were characterized to determine the desirable formulations. The results indicated that radial expansion ratio (1.11-1.67), the solid density (0.71-0.76 g/mL), piece density $(0.20-0.63 \mathrm{~g} / \mathrm{mL})$, porosity $(14.49-72.38 \%)$, hardness $(23-157.73 \mathrm{~N})$, crispness (4.17-13.5), moisture content (3.22-4.39\%), water activity $(0.14-0.36)$ and the water solubility $(7.07-30.80 \%)$ of rice flour and cranberry pomace blend extrudates were varied depending on the combinations of the rice flour and cranberry pomace. The results revealed that up to $20 \%$ cranberry pomace could be added with $75-80 \%$ rice flour to develop high fiber and antioxidant with less carbohydrate cereal/snack products. The utilization of cranberry pomace combining with rice flour through extrusion process can provide a unique opportunity to generate healthier snacks and cereals that have higher fiber and antioxidant and low carbohydrate.

Keywords: cranberry pomace utilization, single screw extrusion, food industry wastes into foods, rice flour

\section{Introduction}

Nowadays, people of all ages are interested in highly nutritious food products which take a less preparation time and convenient to eat due to changing busy lifestyle (Schwartz, Novak, \& Fiore, 2009; Zhou, Mitra, Melnychenko, \& Rizvi, 2021). Snacks and breakfast cereals are on a huge demand because of consumers' preferences in a 'cash-rich, time-poor' lifestyle of the present society. The snacks and cereals are mainly prepared from starchy substances such as rice, corn, wheat which are directly responsible for lacking some essential nutrients (Mitra \& Ramaswamy, 2021; Zhou et al., 2021). This leads to poor nutritional values of products which directly leads to deficiency of micronutrients such as vitamins, minerals, amino acids, fibers and antioxidants in the products. The lack of nutrients in snacks and cereals is not a good correlation with a sound health (Alam, Kaur, Khaira, \& Gupta, 2016; Grasso, 2020; Kocyigit, Koylu, \& Keles, 2006; Mitra \& Ramaswamy, 2021; Zhou et al., 2021). Rice (Oryza Sativa L.) is an important cereal crop and staple food for the larger population worldwide due to its appealing taste and maximum acceptance because it helps in feeling full fast, lowers cholesterol and nourishes gut bacteria. Rice flour contains a small amount of protein. Rice flour is nonallergic and it is a suitable raw material for the manufacturing of gluten-free processed food products such as children's foods, snacks, fermented foods and extrudates cereals (Gong et al., 2017; Guha \& Ali, 2011; Kocyigit et al., 2006). Rice flour alone cannot produce nutritionally rich products and the addition of industrial byproducts which have ample of nutrients and relatively inexpensive can improve nutritional characteristics in processed foods (Grasso, 2020; Ohtsubo, Suzuki, Yasui, \& Kasumi, 2005). The food industrial byproducts (food industrial wastes) are rich in proteins, fiber and other health promoting components and they are cheap (Grasso, 2020). For example, fruit juice processing industries generates many millions of tons of wastes (pomaces) per year. The fruits such as cranberry, apple, strawberry and orange produce their byproduct pomaces after producing juice. The pomaces are considered as waste because of their negative effects on 
sustainability of food processing industry (Grasso, 2020; Mitra, Thapa, Acharya, \& Alim, 2020; Paraman, Sharif, Supriyadi, \& Rizvi, 2015). They cannot be dumped for the field filling because of an uncontrol fermentation which can cause a serious environmental problem (Mitra et al., 2020). The proper treatments before disposal of produced byproducts are required. An innovative technology with viable strategies for converting them to high value foods is required to prevent their disposal as waste and this can lead to rise in sustainability and competitiveness of food industry worldwide. Cranberry pomace is a byproduct of cranberry processing industry and cannot be used for animal feed because of its low protein content. As cranberry pomace is abundant in dietary fibers and phenolic compounds (antioxidant) this byproduct pomace can be converted to value added extruded products (i.e. cereals and snacks) blending with rice flour using extrusion technology.

Extrusion is a process of forcing a material to flow under a variety of conditions through a spaded hole (die) at a predetermined rate to achieve various products (Alam et al., 2016; Harper, 1981; Moraru \& Kokini, 2003). The extrusion process is an efficient continuous process, which uniquely combines several unit operations such as mixing, shearing, heating, pumping, forming, and sizing (Harper, 1981). During the process of extrusion, thermal and shear energies applied to raw blend/food formulation cause structural, chemical and nutritional transformations such as starch gelatinization and degradation, protein denaturation, lipid oxidation, degradation of vitamins, anti-nutrition and phytochemicals, formation of flavors, increase of mineral bioavailability and dietary fiber solubility (Alam et al., 2016; Guha \& Ali, 2011; Guy, 2001; Mitra \& Ramaswamy, 2021; Moraru \& Kokini, 2003; Zhou et al., 2021). The quality of the final extrudates varies with the extruder type (single-screw or twin-screw), extrusion operation conditions (i.e. die temperature, screw speed, feed rate and die size etc.) and the product formulations. It is necessary to understand the effects of extrusion operation variables on the formulations to develop desired extrudates.

The addition of cranberry pomace with rice flour in formulations affects the physicochemical properties (i.e. expansion ratio, densities, porosity, hardness, crispness, moisture content, water activity and water solubility index etc.) of the final extrudates which are directly related to the consumers' acceptance of the extruded products. It is necessary to understand how the cranberry pomace can be converted to develop extruded snacks/cereals. The objective of this study was to convert the cranberry pomace into value added snacks/cereals blending with rice flour using a single screw extruder.

\section{Materials and Method}

\subsection{Materials}

The rice flour was purchased from PGP International- An ABF Ingredients company (USA). The dried cranberry pomace was obtained from cranberry network and cranberry partners, Wisconsin Rapids, USA. The dried cranberry pomace was ground using a grinding machine and the ground cranberry pomace was sieved using a 40-mesh sieve which gave an average $425 \mu \mathrm{m}$ particle size of ground cranberry pomace. 


\section{Macrothink}

\subsection{Rice Flour and Cranberry Pomace Blend Preparation for Extrusion}

Six formulations were prepared by blending rice flour and cranberry pomace for six ratios (cranberry pomace: rice flour). $0,5,10,15,20$ and $25 \%$ cranberry pomaces were blended separately with $100,95,90,85,80$ and $75 \%$ of rice flour using a pilot scale blender (Hobert H - 600, Model: A200T, USA). 35\% water was added gradually to cranberry and rice flour mixture and was blended until reached to a uniform (until no lump was found) mixing of cranberry pomace, rice flour and water together. These six blended formulations were used for extrusion to develop value-added extruded snacks/cereals.

\subsection{Single Screw Extrusion Processing of Rice Flour and Cranberry Pomace Blend}

Tiger 20 single screw extruder (American Extrusion International, USA) as shown in Figure 1 was used in this study to develop cranberry pomace and rice flour blend value-added extruded snacks/cereals. The extruder was assembled with screw, barrel and die (6X $3.8 \mathrm{~mm})$. The extrusion temperature $\left(150^{\circ} \mathrm{C}\right)$, screw speed $(270 \mathrm{rpm})$ and feed rate $(20 \mathrm{Kg} / \mathrm{hr})$ for all six formulations were controlled using a control panel. Extrusion process was started once the temperature reached to $150^{\circ} \mathrm{C}$. The extrudates came through a $3.8 \mathrm{~mm}$ die and was cut into about $15 \mathrm{~mm}$ long cylindrical pieces. The cut extrudates were then dried at $80^{\circ} \mathrm{C}$ for one hour with a hot-air dryer to reach to a moisture content about 3-6\%. The samples were then removed from the dryer and cooled down to room temperature and were place in airtight containers for further analysis.

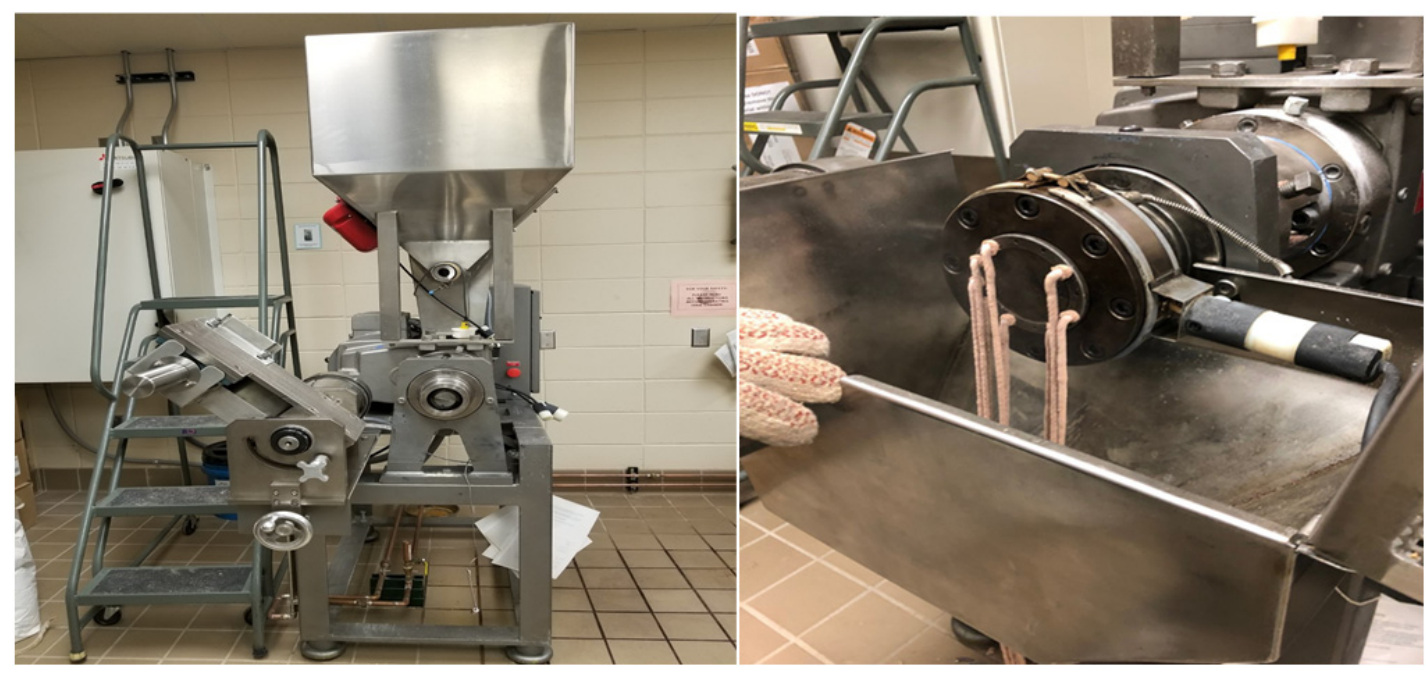

Figure 1. Single screw extruder used in this study (left) and cranberry pomace and rice flour blend extrudates came out through the dies (right) 


\section{Ml Macrothink}

\subsection{Characterization of Rice Flour and Cranberry Pomace Blend Extrudates}

\subsubsection{Expansion Ratio of Extrudates}

Radial expansion ratio, axial expansion ratio and overall expansion ratio were determined for all six formulations to understand the effect of cranberry pomace addition with rice flour on the expansion ratio which was a very important property of extruded snacks/cereals.

The radial expansion ratio was determined by dividing the cross-sectional area of the extrudates $\left(\mathrm{D}_{\mathrm{e}}{ }^{2}\right)$ by the cross-sectional area of the die $\left(\mathrm{D}_{\mathrm{d}}{ }^{2}\right)$. The diameter of the extrudates was measured using a digital caliper. The die diameter was $3.8 \mathrm{~mm}$ and the diameter of 20 samples of each formulation was measured to determine the average radial expansion ratio (Mitra \& Ramaswamy, 2021; Moraru \& Kokini, 2003).

$$
\text { Radial expansion ratio }=\frac{D_{e}^{2}}{D_{d}^{2}}
$$

The overall expansion ratio of the extrudates was measured as the ratio of solid density to the piece density of the extrudates and the axial expansion ratio of the extrudates was determined as the ratio of the overall expansion to the radial expansion of the extrudates (Ali, Hanna, \& Chinnaswamy, 1996; Sumargo, Gulati, Weier, Clarke, \& Rose, 2016; Zhou et al., 2021). Fifteen replications were conducted for each formulation and the average value was reported.

\subsubsection{Solid Density of Extrudates}

The solid density of the extrudates was determined as the ratio of mass to the solid volume of the extrudates. In order to determine the solid volume of the extrudates the extrudates were ground. The ground extrudates were sieved through a 60 -mesh sieve. A $5 \mathrm{~mL}$ graduated cylinder was tarred on a digital scale. The cylinder was then filled to the line with the ground extrudates. The edge of the cylinder was tapped repeatedly until the samples came to a completely settled place. The weight and the volume of the completely settled samples in the cylinder were recorded. Then the solid density was determined using the following equation (Mitra, Alim, \& Meda, 2019; Zhou et al., 2021). Five replications were conducted and the average value of each sample was reported.

$$
\text { Solid density }\left(\frac{g}{m L}\right)=\frac{\text { Mass of ground extrudates }(g)}{\text { Solid volume }(m L)}
$$

\subsubsection{Piece Density of Extrudates}

The piece density of the extrudates was determined as the ratio of mass of the extrudates to the piece volume of the extrudates. The Rapeseed Displacement method as defined by the AACC (2001) was used to determine the piece volume of the extrudates. A $100 \mathrm{~mL}$ graduated cylinder was filled with $10 \mathrm{~g}$ extrudates. Then the graduated cylinder along with extrudates was filled with the rapeseeds by tapping repeatedly until the samples came to a completely settled place. The extrudates and the rapeseeds were taken out from the cylinder and was separated the rapeseeds from the extrudates. The separated rapeseeds were again placed into 


\section{MInstitute Macrothink $_{\text {Ins }}$}

the cylinder and tapped to complete settlement. The volume of the rapeseed after completed settled placed in the cylinder was measured. The piece volume of the extrudates was calculated by subtracting the volume of rapeseeds from the volume $(100 \mathrm{~mL})$ of graduated cylinder (AACC, 2001; Mitra et al., 2019). The piece density of the extrudates was determined using the following equation. Five replications were conducted and the average value of the piece density was reported.

$$
\text { Piece density }\left(\frac{g}{m L}\right)=\frac{\text { Mass of extrudates }(g)}{\text { Piece volume of extrudates }(m L)}
$$

\subsubsection{Porosity of Extrudates}

The porosity (\%) of the extrudates was determined based on the solid density and piece density of the extrudates. The porosity was calculated using the following equation (Mitra et al., 2019; Zhou et al., 2021). Five replications were done and the average value of the porosity of the extrudates was reported.

$$
\text { Porosity }(\%)=\frac{\text { Solid density }- \text { Piece density }}{\text { Solid density }} \times 100
$$

\subsubsection{Hardness and Crispness of Extrudates}

An Instron Machine (Instron Corporation, Norwood, USA) was used to determine the hardness $(\mathrm{N})$ and the crispness of the extrudates. The Bluehill 3 software was used to generate a force-deformation curve to determine the hardness and the crispness of the samples. An extrudate was compressed with a $35 \mathrm{~mm}$ diameter stainless steel probe attached with a $500 \mathrm{~N}$ load cell to break the sample to $80 \%$ strain of the samples. The total strain during the chewing process in the mouth was reported to be about $70 \%$ (Dogan \& Kokini, 2007; Timalsina et al., 2019). So, a complete information on the mechanical behavior of the extrudates without excessive densification can be achieved with $80 \%$ strain of the samples. The pre-test speed $(2 \mathrm{~mm} / \mathrm{s})$, test speed $(1 \mathrm{~mm} / \mathrm{s})$ and post-test speed $(2 \mathrm{~mm} / \mathrm{s})$ were set to perform the compression test. The maximum force from the force-deformation curve required to $80 \%$ strain of the samples was calculated as the hardness of the extrudates. The number of peaks in the force-deformation curve indicated the cell wall-fracture of the sample, which correlated to the crispness (Dogan \& Kokini, 2007; Timalsina et al., 2019). The peaks in the force-deformation curve were counted and the number of peaks was reported as the crispness of the extrudates.

\subsubsection{Moisture Content of Extrudates}

The moisture content was determined by an AOAC air oven method (Horwitz \& Latimer, 2005). Five grams of extrudates were put into a known weight dish. Extrudates samples were dried in an oven at $105^{\circ} \mathrm{C}$ for overnight. The dishes with dried samples were transferred to a desiccator and were measured the weights soon after reaching to a room temperature. The difference between the initial mass and dried-sample mass was the mass of the water in the sample. The moisture content $(\%, w b)$ of the extrudates was determined using the following equation. Five replications were performed to get an average moisture content of the 


\section{Macrothink}

extrudates.

$$
\text { Moisture content }(\%, w b)=\frac{\text { Mass of water of the extrudates }}{\text { Total mass of the extrudates }}
$$

\subsubsection{Water Activity of Extrudates}

The water activity of extrudates was determined using an Aqualab Water Activity Meter 4TE (Corona, CA). A cup filled with extrudates was placed in the water activity meter and the sample chamber lid of the water activity meter was sealed over the extrudate sample. The extrudate was left in the water activity meter until a constant reading was obtained (Mitra et al., 2019; Timalsina et al., 2019). The mean water activity of 5 replications was calculated.

\subsubsection{Water Solubility Index of Extrudates}

The water solubility index determines the behavior of the material in order to decide whether a binder or a stabilizer is needed for further process. The extrudates were ground and 2 grams of the ground extrudates were placed into a centrifuge tube. 25 milliliters $(\mathrm{mL})$ of distilled water at $30{ }^{\circ} \mathrm{C}$ were added to the ground extrudates. After $30 \mathrm{~min}$ standing with intermittent shaking every $5 \mathrm{~min}$, the sample was centrifuged at $5000 \mathrm{rpm}$ for $15 \mathrm{~min}$. The supernatant was decanted into a petridish and was dried at $105^{\circ} \mathrm{C}$ for overnight. The weight of dry solid was determined and the water solubility index (\%) was calculated by the following equation. Three replications were performed to determine an average water solubility index.

$$
\text { Water solubility index }(\%)=\frac{\text { Weight of dry solid in supernatant }}{\text { Weight of dry extrudate }} \times 100
$$

\subsection{Statistical Analysis}

The results are shown as mean \pm standard deviation (SD). The statistical analysis of the data was analyzed using IBM SPSS software version 28. The One-way single factor Analysis of Variance (ANOVA) test was performed for the physicochemical properties of extrudates to determine the significant difference among the six formulations at $\mathrm{P} \leq 0.05$. In order to determine the differences among the results of the mean of the different percentages of cranberry extrudates the Duncan Multiple Range Test (DMRT) was conducted at $\mathrm{P} \leq 0.05$. 


\section{Results and Discussion}

\subsection{Radial, Axial and Overall Expansion Ratios of Rice Flour and Cranberry Pomace Blend Extrudates}

The radial expansion ratio, axial expansion ratio and overall expansion ratio of six different rice flour and cranberry pomace blend extrudates are shown in Figure 2. The results indicated the radial expansion ratio varied from 1.11 to 1.67 , axial expansion ratio varied from 0.85 to 2.33 and overall expansion ratio varied from 1.17 to 3.62 with the variations of cranberry pomace $(0-25 \%)$ and rice flour (100-75\%). The addition of cranberry pomace to the rice flour did not show any ascending or descending trend. The degree of expansion of extrudates for extruded snacks and cereals is corelated to the consumers' acceptance because a light puffed structure with a good texture of cereal/snacks products is desirable. The higher expansion ratio is preferable for the extruded cereal/snack products (Ali et al., 1996; Mitra \& Ramaswamy, 2021; Moraru \& Kokini, 2003; Zhou et al., 2021). The one-way single factor ANOVA results for radial, axial and overall expansion ratios of extrudates are shown in Table 3. The ANOVA results indicated that the null hypothesis of these three types of expansion ratios was rejected because $\mathrm{F}$ value was greater than $\mathrm{F}$ value at the critical point (Fcrit) and the $\mathrm{P}$ value was lower than 0.05 for all three types of expansion ratios of extrudates (Table 3 ). Since the F value exceeded the Fcrit the sample means tested were different and the group means were not equal. The $\mathrm{P}$ value $<0.05$ indicated a significant difference between the samples tested. The lower $\mathrm{P}$ value designated the more significant difference between the groups (Mason, Gunst, \& Hess, 2003; Mitra et al., 2019; Mitra, Chang, \& Yoo, 2011; Mitra, Meda, \& Green, 2013; Timalsina et al., 2019). Since ANOVA analysis cannot determine whether each individual mean is significantly different from all of the other means of the group, a Duncan's Multiple Range Test (DMRT) was performed. The experimental results (Figure 2) and the DMRT results showed that the highest radial expansion ratio (1.67) was achieved for the cranberry pomace and rice flour (20:80) blend extrudates. This might be happened the higher amount of cranberry pomace (20\%) might entrap the higher amounts of gas inside the extrudates, and the less amount of rice flour $(80 \%)$ might get a favorable condition for the higher amount of starch gelatinization (Zhou et al., 2021). However, cranberry pomace showed very variable matrix of expansion capacity of extrudates because $15 \%$ cranberry pomace gave the lowest radial expansion ratio (1.11) and the second highest radial expansion ratio was given by $5 \%$ cranberry pomace with $95 \%$ rice flour. The zero percent cranberry pomace $(100 \%$ rice flour) and the highest $25 \%$ cranberry pomace $(75 \%$ rice flour) followed the expansion ratio of $20 \%$ cranberry pomace extrudate formulation, respectively. 


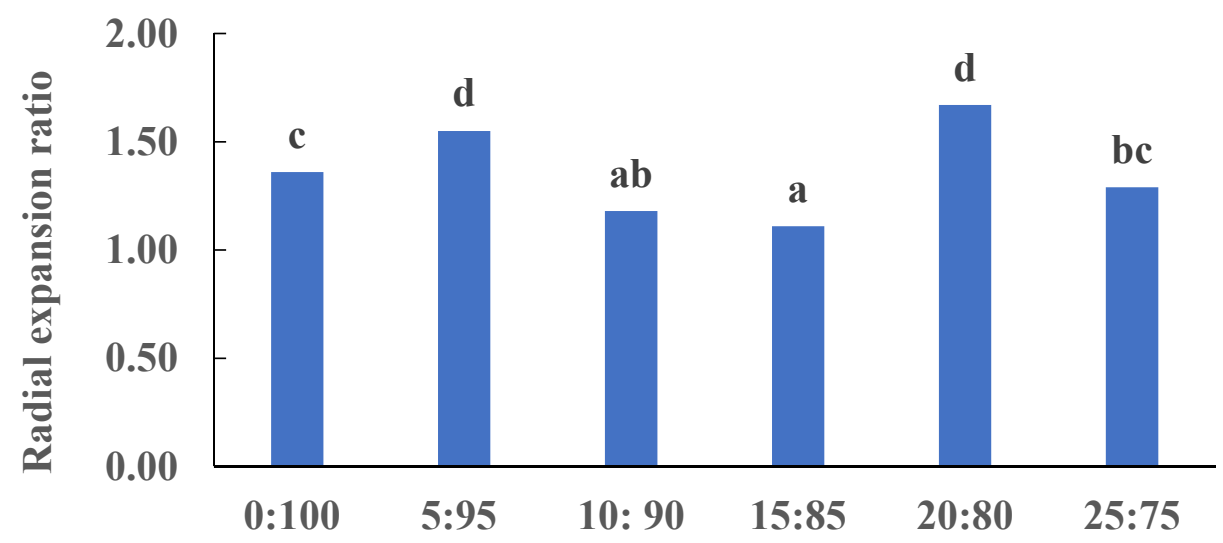

Formulations (Cranberry pomace:Rice flour)
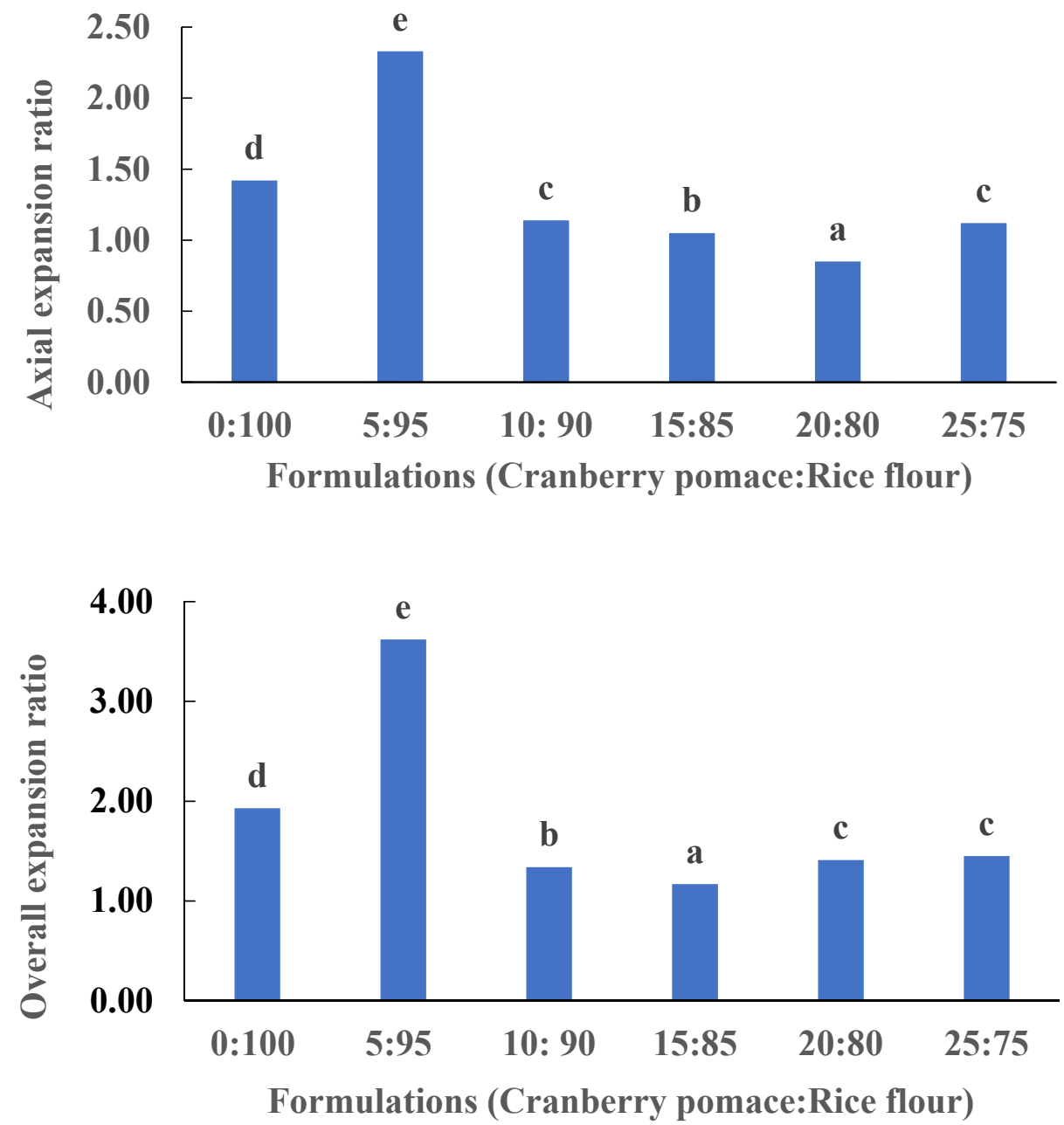

Figure 2. The radial expansion ratio (top), axial expansion ratio (middle) and overall expansion ratio (bottom) of six different cranberry pomace and rice flour blend extrudates developed using a single screw extruder. The bar with different letters denotes significant differences between samples $(\mathrm{P}<0.05)$ 


\section{Macrothink}

The axial expansion ratio of extrudates shown in Figure 2 (middle) revealed that the highest axial expansion ratio (2.33) was provided by the formulation of $5 \%$ cranberry pomace and $95 \%$ rice flour blend extrudate and the lowest expansion ratio $(0.85)$ was provided by the formulation of $20 \%$ cranberry pomace and $80 \%$ rice flour blend extrudate. Axial expansion of the extrudates is driven by the viscous forces of the blend formulations (Sumargo et al., 2016; Zhou et al., 2021). In this case, the higher amount of cranberry pomace might increase the viscous force, consequently, decrease the axial expansion ratio of extrudates.

The overall expansion ratio of extrudates shown in Figure 2 (bottom) indicated that the highest overall expansion ratio (3.62) was provided by the formulation of $5 \%$ cranberry pomace and $95 \%$ rice flour blend extrudate and the lowest expansion ratio (1.17) was provided by the formulation of $15 \%$ cranberry pomace and $85 \%$ rice flour blend extrudate. The overall expansion ratio of extrudates did not show any ascending or descending pattern with cranberry pomace. This phenomenon might be depended on the radial expansion ratio of the extrudates because the radial expansion dominated the overall expansion and axial expansion, consequently, the radial expansion increased the overall expansion (Ali et al., 1996; Sumargo et al., 2016; Zhou et al., 2021).

Table 1 . The results of solid density, piece density and porosity of cranberry pomace and rice flour blend extruded products developed using a single screw extruder

\begin{tabular}{cccc}
\hline $\begin{array}{c}\text { Formulations } \\
\begin{array}{c}\text { Cranberry pomace: } \\
\text { Rice flour })\end{array}\end{array}$ & Solid density $(\mathrm{g} / \mathrm{mL})$ & $\begin{array}{c}\text { Piece density } \\
(\mathrm{g} / \mathrm{mL})\end{array}$ & Porosity $(\%)$ \\
\hline $0: 100$ & $0.72^{\mathrm{a}} \pm 0.01$ & $0.37^{\mathrm{b}} \pm 0.01$ & $48.24^{\mathrm{e}} \pm 0.43$ \\
$5: 95$ & $0.71^{\mathrm{a}} \pm 0.01$ & $0.20^{\mathrm{a}} \pm 0.01$ & $72.38^{\mathrm{f}} \pm 0.35$ \\
$10: 90$ & $0.76^{\mathrm{c}} \pm 0.00$ & $0.57^{\mathrm{e}} \pm 0.02$ & $25.22^{\mathrm{b}} \pm 0.18$ \\
$15: 85$ & $0.73^{\mathrm{b}} \pm 0.00$ & $0.63 \mathrm{f} \pm 0.03$ & $14.49^{\mathrm{a}} \pm 0.34$ \\
$20: 80$ & $0.73^{\mathrm{b}} \pm 0.00$ & $0.52^{\mathrm{d}} \pm 0.01$ & $29.16^{\mathrm{c}} \pm 0.24$ \\
$25: 75$ & $0.71^{\mathrm{a}} \pm 0.00$ & $0.49^{\mathrm{c}} \pm 0.01$ & $30.93^{\mathrm{d}} \pm 0.36$ \\
\hline
\end{tabular}

Means within a column with different letters are significantly different $(\mathrm{P}<0.05)$

\subsection{Solid density, piece density and porosity of rice flour and cranberry pomace blend extrudates}

The solid density, piece density and porosity of six formulations of the rice flour and cranberry pomace blend extrudates are shown in Table 1 . The results indicated that the solid density of extrudates ranged from 0.71 to $0.76 \mathrm{~g} / \mathrm{mL}$, piece density of extrudates ranged from 0.20 to $0.63 \mathrm{~g} / \mathrm{mL}$ and the porosity of extrudates ranged from 14.49 to $72.38 \%$ (Table 1 ). The cranberry pomace content of the six different extrudates affected the solid density, piece 
density and porosity of the extrudates significantly because the ANOVA results (Table 3) indicated $\mathrm{P}<0.05$ and $\mathrm{F}$ value $>$ Fcrit (Mason et al., 2003; Mitra et al., 2019, 2013). The cranberry pomace showed the variable effects depending on the amount of cranberry pomace with the rice flour in the formulations.

The highest solid density $(0.76 \mathrm{~g} / \mathrm{mL})$ was given by the formulation of $10 \%$ cranberry pomace and $90 \%$ rice flour blend extrudates and the lowest solid density $(0.71 \mathrm{~g} / \mathrm{mL})$ was given by two formulations ( 5 and $25 \%$ cranberry pomace). The DMRT analysis (Table 1 ) was able to rank the solid density of extrudates. This solid density result of this study was in the disagreement of the solid density of dried horseradish (Mitra et al., 2019). However, the solid density result of this study was in the agreement with the solid density of milk protein and rice flour blend extrudates (Zhou et al., 2021). This phenomenon might be happened because of variable matrix of ingredients of the formulations. In this study, the cranberry pomace had a variable effect in the matrix of the final extrudates which resulted in a variable solid density value of the different formulations of rice flour and cranberry pomace extrudates.

The highest piece density $(0.63 \mathrm{~g} / \mathrm{mL})$ was given by the formulation of $15 \%$ cranberry pomace and $85 \%$ rice flour blend extrudates and the lowest piece density $(0.20 \mathrm{~g} / \mathrm{mL})$ was given by the formulation of 5\% cranberry pomace and $95 \%$ rice flour blend extrudates (Table 1). The DMRT analysis (Table 1) divided the extrudates in six different groups indicating each formulation was separated from any other formulations. The cranberry pomace had a variable effect on the piece density of the extrudates and was not able to show an ascending or a descending trend. However, the radial expansion ratio of extrudates shown in Figure 2 (top) was inversely related to the piece density of the cranberry pomace and rice flour blend extrudates (Table 1). This inverse correlation result was in the agreement with some previous studies of extruded products (Alam et al., 2016; Ali et al., 1996; Mitra \& Ramaswamy, 2021; Moraru \& Kokini, 2003; Zhou et al., 2021). The low piece density $(0.02-0.70 \mathrm{~g} / \mathrm{mL})$ of extruded products are desirable (Zhou et al., 2021). The cranberry pomace and rice flour blend extrudates with low piece density $(0.20-0.63 \mathrm{~g} / \mathrm{mL})$ indicated that the extrudates developed in this study were suitable for snacks or cereal products.

The expansion or puffing in extrudates is occurred due to the creation of air pockets or gas cells during the extrusion cooking process which decreased the piece density of the products (Ali et al., 1996). The space of the air pockets/gas cells in the product is a measure of porosity and the higher porosity of the product gives the better quality of snack/cereal products (Ali et al., 1996; Zhou et al., 2021). The highest porosity $(72.38 \%$ ) was given by the formulation of $5 \%$ cranberry pomace and $95 \%$ rice flour blend extrudates and the lowest porosity $(14.49 \%$ ) was given $15 \%$ cranberry pomace and $85 \%$ rice flour blend extrudates. The DMRT analysis (Table 1) divided the extrudates into six different groups indicating each formulation was different from any other formulations. There was no linear or inversely linear relationship between cranberry pomace and porosity of the extrudates, but the cranberry pomace influenced the porosity significantly $(\mathrm{P}<0.05)$. The porosity of the extrudates was linearly related to the radial expansion ratio of extrudates (Figure 2) and was inversely related to the piece density of the cranberry pomace and rice flour blend extrudates. The correlation results of this study were similar to several studies of extrudate products 
(Alam et al., 2016; Ali et al., 1996; Moraru \& Kokini, 2003; Zhou et al., 2021).
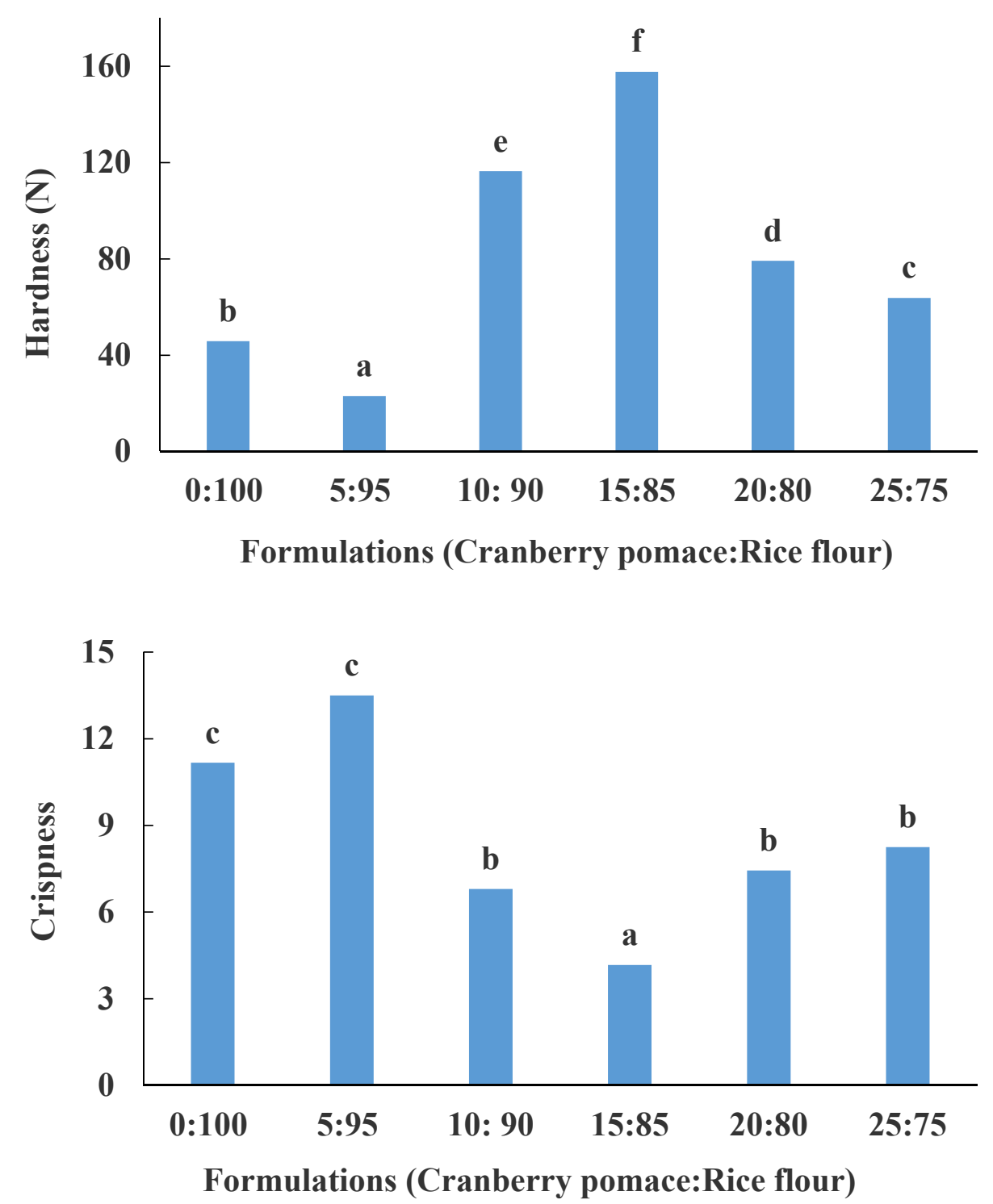

Figure 3. The hardness $(\mathrm{N})$ and the crispness of six different cranberry pomace and rice flour blend extrudates developed using a single screw extruder. The bar with different letters denotes significant differences between samples $(\mathrm{P}<0.05)$.

\subsection{Hardness and crispness of rice flour and cranberry pomace blend extrudates}

The hardness and crispness of six formulations of the rice flour and cranberry pomace blend extrudates are shown in Figure 3. The results indicated that the hardness $(\mathrm{N})$ of extrudates ranged from 23 to $157.73 \mathrm{~N}$, and the crispness of extrudates ranged from 13.5 to 4.17 . The cranberry pomace contents and the rice flour contents of the six different extrudates affected the hardness and crispness of the extrudates significantly because the ANOVA results (Table 


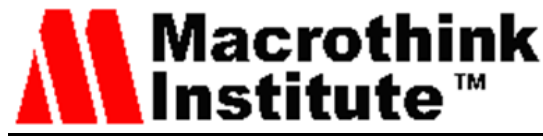

3) indicated $\mathrm{P}<0.05$ and $\mathrm{F}$ value $>$ Fcrit (Mason et al., 2003; Mitra et al., 2019, 2013; Timalsina et al., 2019). The experimental results (Figure 3) and the DMRT analysis indicated the highest hardness $(157.73 \mathrm{~N})$ and the lowest crispness $(4.17)$ were achieved for the $15 \%$ cranberry pomace and $85 \%$ rice flour blend extrudate. The lowest hardness $(23 \mathrm{~N})$ and the highest crispness (13.5) were achieved for the 5\% cranberry pomace and $95 \%$ rice flour blend extrudate. The $20-25 \%$ cranberry addition with $80-75 \%$ rice flour showed relatively moderate hardness (79.24-63.82 N) and crispness (7.44-8.25).

The hardness and the crispness of the extrudates snacks and cereals are very important properties because they influence the consumers' acceptance of the extruded products. The lower hardness and the higher crispness are desirable (Zhou et al., 2021). The lower hardness of extrudates increased the expansion ratio and decreased the piece density. The crispness describes the number of fracture events occurring during compression, which is correlated with aggregates and fractions of ingredients of extrudates (Moraru \& Kokini, 2003; Zhou et al., 2021). The results of this study revealed that the hardness of the six different rice flour and cranberry pomace extrudates was linearly related to piece density of the extrudates and inversely related to expansion ratio of extrudates. The crispness of the cranberry pomace and rice flour blend extrudates was increased with the expansion ratio of extrudates and decreased with the piece density of extrudates. These trends of the hardness and crispness of this study were in the agreement of some other studies of extruded products and sweet potato chips (Alam et al., 2016; Ali et al., 1996; Moraru \& Kokini, 2003; Sumargo et al., 2016; Timalsina et al., 2019; Zhou et al., 2021).

Table 2. The results of moisture content, water activity and water solubility index of cranberry pomace and rice flour blend extruded products developed using a single screw extruder

\begin{tabular}{cccc}
\hline $\begin{array}{c}\text { Formulations } \\
\begin{array}{c}\text { Cranberry pomace: Rice } \\
\text { flour })\end{array}\end{array}$ & $\begin{array}{c}\text { Moisture content } \\
(\%, \mathrm{wb})\end{array}$ & Water activity & $\begin{array}{l}\text { Water solubility } \\
\text { index }(\%)\end{array}$ \\
\hline $0: 100$ & $3.40^{\mathrm{a}} \pm 0.24$ & $0.20^{\mathrm{b}} \pm 0.01$ & $16.90^{\mathrm{b}} \pm 0.74$ \\
$5: 95$ & $3.22^{\mathrm{a}} \pm 0.12$ & $0.14^{\mathrm{a}} \pm 0.00$ & $30.80^{\mathrm{d}} \pm 0.89$ \\
$10: 90$ & $3.56^{\mathrm{a}} \pm 0.59$ & $0.26^{\mathrm{c}} \pm 0.01$ & $23.17^{\mathrm{c}} \pm 0.70$ \\
$15: 85$ & $4.39^{\mathrm{b}} \pm 0.53$ & $0.36^{\mathrm{d}} \pm 0.02$ & $16.02^{\mathrm{b}} \pm 1.01$ \\
$20: 80$ & $3.59^{\mathrm{a}} \pm 0.26$ & $0.27^{\mathrm{c}} \pm 0.00$ & $7.07^{\mathrm{a}} \pm 0.08$ \\
$25: 75$ & $3.45^{\mathrm{a}} \pm 0.37$ & $0.21^{\mathrm{b}} \pm 0.01$ & $7.90^{\mathrm{a}} \pm 0.38$ \\
\hline
\end{tabular}

Means within a column with different letters are significantly different $(\mathrm{P}<0.05)$ 
3.4 Moisture Content, Water Activity and Water Solubility Index of Rice Flour and Cranberry Pomace Blend Extrudates

The results revealed that the final moisture content of rice flour and cranberry pomace blend extrudates varied from 3.22 to $4.39 \%(\mathrm{wb})$, the water activity of rice flour and cranberry pomace blend extrudates varied from 0.14 to 0.36 and the water solubility index of rice flour and cranberry pomace blend extrudates varied from 7.07 to $30.80 \%$ depending on the rice flour contents and cranberry pomace contents in the extrudate formulations (Table 2). The one-way single factor ANOVA results (Table 3) indicated that the $\mathrm{P}$ value for the moisture content, water activity and water solubility index of rice flour and cranberry pomace blend extrudates was smaller than 0.05 . The lower $P$ value indicated the more significant difference among the six different extrudate formulations (Mason et al., 2003; Mitra et al., 2011; Mitra, Kim, \& Chang, 2007; Mitra et al., 2013). The F value was greater than F value at the critical point (Fcrit) for the moisture content, water activity and water solubility index of the six different extrudates. The $\mathrm{F}$ value result indicated that the means of moisture content, water activity and water solubility index of six different rice flour and cranberry pomace formulations were different, and the group means were not equal (Mason et al., 2003; Mitra et al., 2007, 2013). The Duncan's Multiple Range Test (DMRT) was conducted to investigate whether each individual mean was significantly different from all the other means of the group or not. The DMRT results (Table 2) indicated that the moisture content, water activity and water solubility index of each rice flour and cranberry pomace blend extrudate formulation were significantly different for all other extrudate samples.

Table 3. The ANOVA results of physicochemical properties of cranberry pomace and rice flour blend extruded products developed using a single screw extruder

\begin{tabular}{lcccccc}
\hline Physicochemical & $\begin{array}{c}\text { Sum of } \\
\text { Pquares } \\
\text { Properties of extrudates }\end{array}$ & $\begin{array}{c}\text { Degree } \\
\text { of } \\
\text { Freedom } \\
\text { (SS) }\end{array}$ & $\begin{array}{c}\text { Mean } \\
\text { Square } \\
\text { (MS) }\end{array}$ & F-Value & Fcrit & P-value \\
\hline Radial expansion ratio & 1.300 & 5 & 0.260 & 19.50 & 2.57 & $<0.001$ \\
Solid density (g/mL) & 0.004 & 5 & 0.001 & 33.05 & 3.20 & $<0.001$ \\
Piece density (g/mL) & 1.088 & 5 & 0.218 & 844.05 & 2.45 & $<0.001$ \\
Porosity $(\%)$ & 6363.27 & 5 & 1272.66 & 11841.87 & 3.11 & $<0.001$ \\
Hardness (N) & 100896.49 & 5 & 20179.09 & 261.72 & 2.40 & $<0.001$ \\
Crispness & 417.485 & 5 & 83.49 & 38.70 & 2.40 & $<0.001$ \\
Moisture content $(\%)$ & 4.166 & 5 & 0.833 & 5.51 & 2.62 & 0.002 \\
Water activity & 0.145 & 5 & 0.029 & 394.45 & 2.62 & $<0.001$ \\
Water solubility index $(\%)$ & 1232.766 & 5 & 246.55 & 494.76 & 3.11 & $<0.001$ \\
\hline
\end{tabular}

The moisture content and water activity of the food products affect the shelf-life of the products. The lower moisture content (6-8\%) and the water activity less than 0.6 of snacks 
and cereals products are expected for the longer shelf life by prohibiting microbial growth in the foods. The water activity 0.61 is the lowest value required for microbial growth because the microbial growth on set water activity of any materials is 0.6 (Mitra et al., 2019). The water activity results indicated that the water activity $(0.14-0.36)$ of all six formulations of rice flour and cranberry pomace blend extrudates was very lower than the microbial growth on set water activity. The results showed that all rice flour and cranberry pomace blend extruded products were shelf-stable product and could be stored for a longer period for consumption (Zhou et al., 2021). The water activity and moisture content results also indicated that water activity of rice flour and cranberry pomace blend extrudates decreased with the decreased moisture content of rice flour and cranberry pomace blend extrudates. This linear relationship between moisture content and water activity of rice flour and cranberry pomace extrudates was in the agreement of horseradish drying studies (Guragain \& Mitra, 2020; Mitra et al., 2019). The lower water solubility index is a good measure of better polymerization in the extrudates. The lower water solubility index of cereal products is desirable because the cereals are usually consumed soaking in the milk. The lower water solubility index of the products can keep the crunchiness longer, consequently, increase the consumer's acceptance. The water solubility index results (Table 2) revealed that 20-25 cranberry pomace with $80-75 \%$ rice flour blend formulations became desirable by achieving lower water solubility index (7.07-7.90\%). This phenomenon might be the maximum starch gelatinization was occurred due to higher amount of feed moisture with a lower level of rice flour in the feed formulation (Guha \& Ali, 2011; Sumargo et al., 2016).

\section{Conclusions}

Cranberry juice processing industrial byproduct cranberry pomace was converted to foods (snacks/cereals) blending with rice flour using a single screw extruder. The addition of cranberry pomace with rice flour had a very significant effect $(\mathrm{P}<0.05)$ on the physicochemical properties of final rice flour and cranberry pomace blend extrudates. The cranberry pomace and rice flour affected the solid density piece density, porosity, hardness, crispness, moisture content, water activity and water solubility index of extrudates at variable levels significantly. There was a linear relationship between expansion ratio and crispness of extrudates. The expansion ratio was inversely related to hardness and piece density of rice flour and cranberry pomace blend extrudates. Considering desirable physicochemical propertied of rice flour and cranberry pomace blend extrudates, up to $20 \%$ cranberry pomace could be added with $75-80 \%$ rice flour for developing quality cranberry pomace and rice flour blend extrudates for value-added extruded snacks/cereals. Utilization of cranberry pomace for value-added products will not only provide health benefits to consumers but also help in the growth of cranberry juice processing industries. The developed rice flour and cranberry pomace blend extruded products would be nutritionally healthy with higher fiber and antioxidant and less carbohydrate.

\section{Acknowledgments}

The research was funded by the Evelyn Van Donk Steenbock Chair grant and by the Maybelle Ranney Price Professorship grant, University of Wisconsin-Stout, USA. The 
cranberry pomaces were donated by Cranberry Partners /Cranberry Network LLC (Rapids, WI, USA).

\section{References}

AACC, (2001). Approved Methods of Analysis. In Method 10-05.01. Guidelines for Measurement of Volume by Rapeseed Displacement. https://doi.org/10.1094/AACCIntMethod-10-05.01

Alam, M. S., Kaur, J., Khaira, H., \& Gupta, K. (2016). Extrusion and Extruded Products: Changes in Quality Attributes as Affected by Extrusion Process Parameters: A Review. Critical Reviews in Food Science and Nutrition, 56(3), 445-473. https://doi.org/10.1080/10408398.2013.779568

Ali, Y., Hanna, M. A., \& Chinnaswamy, R. (1996). Expansion characteristics of extruded corn grits. LWT - Food Science and Technology, 29(8), 702-707. https://doi.org/10.1006/fstl.1996.0109

Dogan, H., \& Kokini, L. J. (2007). Psychophysical Markers for Crispness and Influence of Phase Behavior and Structure. Journal of Texture Studies, 38(3), 324-354. https://doi.org/10.1111/j.1745-4603.2007.00100.x

Gong, E. S., Luo, S. J., Li, T., Liu, C. M., Zhang, G. W., Chen, J., ... Liu, R. H. (2017). Phytochemical profiles and antioxidant activity of brown rice varieties. Food Chemistry, 227, 432-443. https://doi.org/10.1016/j.foodchem.2017.01.093

Grasso, S. (2020). Extruded snacks from industrial by-products: A review. Trends in Food Science and Technology, 99, 284-294. https://doi.org/10.1016/j.tifs.2020.03.012

Guha, M., \& Ali, S. Z. (2011). Changes in rheological properties of rice flour during extrusion cooking. Journal of Texture Studies, 42(6), 451-458. https://doi.org/10.1111/j.1745-4603.2011.00306.x

Guragain, M., \& Mitra, P. (2020). Empirical Modeling of Hot Air-Drying Kinetics of Horseradish Dehydration. Journal of Food Industry, 4(1), 44-58. https://doi.org/10.5296/jfi.v4i1.17152

Guy, R. (2001). Extrusion Cooking: Technologies and Applications. In Woodhead Publishing Limited. https://doi.org/10.1533/9781855736313.1.5

Harper, J. M. (1981). Extrusion offoods. Boca Raton, Florida.: CRC Press, Inc.

Horwitz, W., \& Latimer, G. W. (2005). Official methods of analysis of AOAC International. Gaithersburg, Md.: AOAC International.

Kocyigit, A., Koylu, A. A., \& Keles, H. (2006). Effects of pistachio nuts consumption on plasma lipid profile and oxidative status in healthy volunteers. Nutrition, Metabolism and Cardiovascular Diseases, 16(3), 202-209. https://doi.org/10.1016/j.numecd.2005.08.004

Mason, R. L., Gunst, R. F., \& Hess, J. L. (2003). Statistical design and analysis of 
experiments: with applications to engineering and science (Vol. 474). John Wiley \& Sons.

Mitra, P., Alim, A., \& Meda, V. (2019). Effect of Hot Air Thin Layer Drying Temperature on Physicochemical and Textural Properties of Dried Horseradish. Journal of Food Industry, 3(1), 1-18. https://doi.org/10.5296/jfi.v3i1.15721

Mitra, P., Chang, K. S., \& Yoo, D. S. (2011). Kaempferol Extraction from Cuscuta reflexa using Supercritical Carbon Dioxide and Separation of Kaempferol from the Extracts. In International Journal of Food Engineering, 7(4), 1-15. https://doi.org/10.2202/1556-3758.1768

Mitra, P., Kim, E.-M., \& Chang, K. S. (2007). Optimization of the processing parameters for green banana chips and packaging within polyethylene bags. Food Science and Biotechnology, 16(6), 889-893.

Mitra, P., Meda, V., \& Green, R. (2013). Effect of drying techniques on the retention of antioxidant activities of Saskatoon berries. International Journal of Food Studies, 2, 224-237. https://doi.org/10.7455/ijfs/2.2.2013.a8

Mitra, P., \& Ramaswamy, H. S. (2021). Artificial Neural Network (ANN ) modeling to predict the twin-screw extrusion processing variables of soy protein isolate and corn flour blend formulations on the physical properties of extrudates. Journal of the Saudi Society for Food and Nutrition, 14(1), 55-67.

Mitra, P., Thapa, R., Acharya, B., \& Alim, A. (2020). Optimization of wheat flour, pumpkin flour and cranberry pomace blend formulations based on physicochemical properties of value-added cookies. Journal of the Saudi Society for Food and Nutrition, 13(1), 46-58.

Moraru, C. I., \& Kokini, J. L. (2003). Nucleation and Expansion During Extrusion and Microwave Heating of Cereal Foods. Comprehensive Reviews in Food Science and Food Safety, 2, 147-165. https://doi.org/10.1111/j.1541-4337.2003.tb00020.x

Ohtsubo, K., Suzuki, K., Yasui, Y., \& Kasumi, T. (2005). Bio-functional components in the processed pre-germinated brown rice by a twin-screw extruder. Journal of Food Composition and Analysis, 18(4), 303-316. https://doi.org/10.1016/j.jfca.2004.10.003

Paraman, I., Sharif, M. K., Supriyadi, S., \& Rizvi, S. S. H. (2015). Agro-food industry byproducts into value-added extruded foods. Food and Bioproducts Processing, 96, 78-85. https://doi.org/10.1016/j.fbp.2015.07.003

Schwartz, M. B., Novak, S. A., \& Fiore, S. S. (2009). The Impact of Removing Snacks of Low Nutritional Value from Middle Schools. Health Education \& Behavior, 36(6), 999-1011. https://doi.org/10.1177/1090198108329998

Sumargo, F., Gulati, P., Weier, S. A., Clarke, J., \& Rose, D. J. (2016). Effects of processing moisture on the physical properties and in vitro digestibility of starch and protein in extruded brown rice and pinto bean composite flours. Food Chemistry, 211, 726-733. https://doi.org/10.1016/j.foodchem.2016.05.097 


\section{Macrothink}

Journal of Food Industry

ISSN 1948-545X 2021, Vol. 5, No. 1

Timalsina, P., Prajapati, R., Bhaktaraj, S., Shrestha, R., Shrestha, S., \& Mitra, P. (2019). Sweet potato chips development and optimization of chips processing variables. Open Agriculture, 4(1), 118-128. https://doi.org/10.1515/opag-2019-0011

Zhou, R., Mitra, P., Melnychenko, A., \& Rizvi, S. S. H. (2021). Quality attributes and rheological properties of novel high milk protein-based extrudates made by supercritical fluid extrusion. International Journal of Food Science and Technology, 56(8), 3866-3875. https://doi.org/10.1111/ijfs.15003

\section{Copyright Disclaimer}

Copyright for this article is retained by the author(s), with first publication rights granted to the journal.

This is an open-access article distributed under the terms and conditions of the Creative Commons Attribution license (http://creativecommons.org/licenses/by/4.0/). 